\title{
FACULTY DEVELOPMENT SCHOLARSHIP
}

AN ANALYSIS OF TO IMPROVE THE ACADEMY, 1982-2011

Kathryn E. Linder

Suffolk University

Suzanna Klaf

Fairfield University

As To Improve the Academy enters its thirty-second year, this chapter offers a retrospective to bonor the bistory of the field through a timely analysis of the content published in TIA and editorial and authorship trends over the previous three decades. Frequency distributions identify the most published authors, their institutional affiliations, the most written about topics, and patterns of collaborative authorship in volumes 1 (1982) through 30 (2011), and findings from a citation analysis of ten years of TIA (volumes 21-30), highlight trends in resources cited and types of resources.

The volumes of To Improve the Academy (TIA) have been an important set of resources to introduce us to the fields of professional, faculty, and organizational development. With fewer than ten years of faculty development experience between us, we find ourselves frequently looking to TIA to inform us about best practices with program 
development, assessment, classroom practice, and the scholarship of teaching and learning, among other topics, as we establish ourselves as professionals within the field (both of us work in teaching centers-one as a director and the other as an associate director). Robert Boice (2000) advises new faculty to "learn about academic culture early, patiently" (p. 211). As junior scholars in faculty development, we have found TIA to be a foundational tool generally, and especially for those early in their faculty development careers. On reflection, we realized that an analysis of TIA volumes, similar to those conducted in other fields (see Blancher, Buboltz, \& Soper, 2010; Pelsma \& Cesari, 1989; Tight, 2009; Williams \& Buboltz, 1999), would help us to explore our profession even further.

This retrospective also honors the history of the field, for it is through looking back and reflecting on the past that we can look ahead, begin a dialogue, and explore together the future directions for scholarship in TIA. If $T I A$ is to expand beyond what appears to be its current purpose as a repository for chapters by practitioners in the field of faculty development, and particularly POD members, then now is a time to begin to explore how it compares with other publications in the field, the contributors it attracts, and the most frequent topics published in it. This chapter is not an exhaustive analysis of the past thirty years of TIA (due to time and resource constraints, this was not a possibility), but we do offer a jumpingoff point for further conversations and analysis of one of our field's primary publications, certainly a standard reference for both of us.

Our research questions and analysis were primarily designed to help us discover TIA trends. Some topics seem to appear more than others in $T I A$, and certain authors are frequent contributors, but what is the actual breakdown of themes, editor and author demographics, and citation sources for this publication that is now thirty years old? Other questions guided our analysis as well:

- What trends can we identify in editorship and authorship in TIA?

- What is the publication frequency of individual authors in TIA?

o How diverse is the author base?

- What resources are authors citing in TIA chapters?

o What seem to be the trusted sources of information in terms of both medium and particular titles?

- What are the most popular topics that are published in TIA? Does the popularity of certain topics change over time?

This analysis seeks to answer some of these questions. We present these data to two main audiences: members of POD who have previously 
published in TIA or plan to publish in it in the future and the leadership of the POD organization, who may find the results helpful in shaping of the role of TIA within POD in the future.

We first explore the editorship of the journal to learn more about editors and associate editor characteristics over time. Second, we use frequency distributions to identify the most published authors and their institutional affiliations, the most written-about topics, and patterns of collaboration across institutions in volumes 1 (1982) through 30 (2011). Third, we discuss the findings from a citation analysis of ten years of TIA (volumes 21-30), noting the most frequently cited resources, as well as trends concerning the types of resources being cited. At the conclusion of the chapter, we explore what some of these trends may mean for current and future scholars of faculty development.

\section{Three Decades of TIA, 1982-2011}

For the editor, author, section, and topic coding analysis of this chapter, we include thirty volumes (see table 10.1), which amount to 587 chapters,

\section{Table 10.1 TIA by Volume and Year of Publication}

\begin{tabular}{lr}
\multicolumn{2}{c}{$\begin{array}{c}\text { Volumes 1-10 } \\
(1982-1991)\end{array}$} \\
\hline Volume & $\begin{array}{r}\text { Year } \\
\text { Volume 1 }\end{array}$ \\
Volume 2 & 1982 \\
Volume 3 & 1983 \\
Volume 4 & 1984 \\
Volume 5 & 1986 \\
Volume 6 & 1987 \\
Volume 7 & 1988 \\
Volume 8 & 1989 \\
Volume 9 & 1990 \\
Volume 10 & 1991
\end{tabular}

\begin{tabular}{lr}
$\begin{array}{c}\text { Volumes 11-20 } \\
\text { (1992-2002) }\end{array}$ \\
\hline Volume & Year \\
Volume 11 & 1992 \\
Volume 12 & 1993 \\
Volume 13 & 1994 \\
Volume 14 & 1995 \\
Volume 15 & 1996 \\
Volume 16 & 1997 \\
Volume 17 & 1998 \\
Volume 18 & 2000 \\
Volume 19 & 2001 \\
Volume 20 & 2002
\end{tabular}

\begin{tabular}{lr}
\multicolumn{2}{|c}{$\begin{array}{c}\text { Volumes 21-30 } \\
\text { (2003-201 1b) }\end{array}$} \\
\hline Volume & Year \\
Volume 21 & 2003 \\
Volume 22 & 2004 \\
Volume 23 & 2005 \\
Volume 24 & 2006 \\
Volume 25 & 2007 \\
Volume 26 & 2008 \\
Volume 27 & 2009 \\
Volume 28 & 2010 \\
Volume 29 & $2011 \mathrm{a}$ \\
Volume 30 & $2011 \mathrm{~b}$
\end{tabular}

Note: The publication years conflict in the print volumes versus online citations of TIA. Hoag Holmgren, executive director of the Professional and Organizational Development Network, clarified the correct dates for each volume through e-mail correspondence. There are two 2011 publications because Jossey-Bass, the publisher, changed the publication conventions with volume 30 . Traditionally TIA was published in October for the POD Network Conference but carried the next year's date. Starting with volume 30 , the listed publication date is the same as the actual publication date. Thus, both volumes 29 and 30 have a 2011 publication date. 
Figure 10.1 Number of Chapters per TIA Volume, 1982-2011b

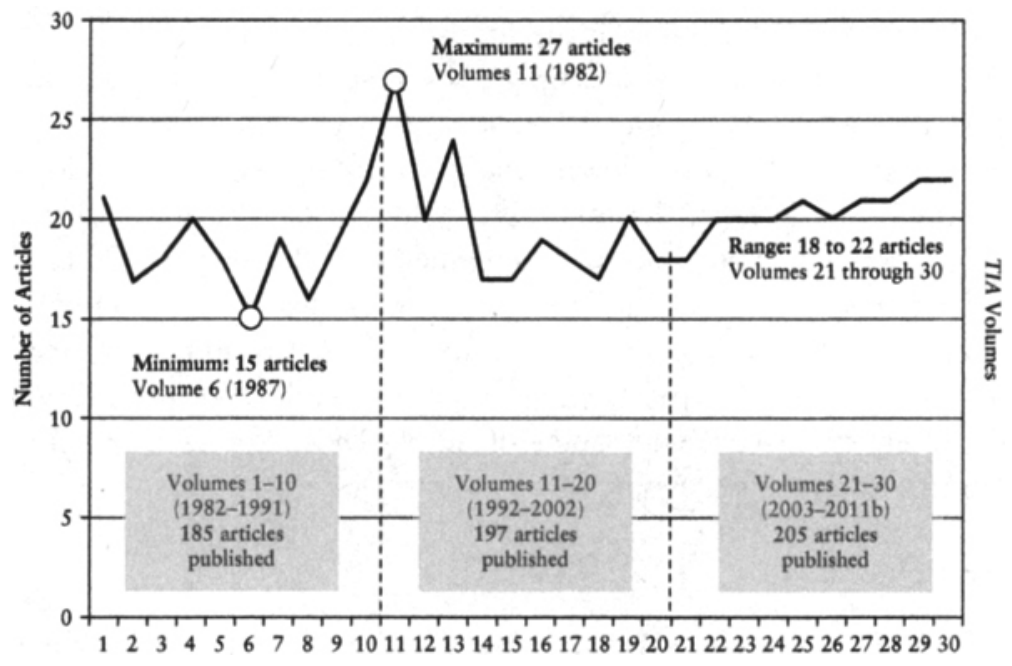

48 unique editors and associate editors, and 808 unique authors. For the citation analysis, we focus on ten volumes (21-30) and analyze 4,485 citations from 205 chapters.

Between 1982 and 2011b, 587 chapters have been published in TIA. The number of chapters published has increased over this three-decade period from 185 published between 1982 and 1991 to 205 published between 2003 and 2011b (see figure 10.1).

Also worth noting is the publication's audience. During its first decade (1982-1991), TIA provided "resources for student, faculty, \& institutional development," and from 1992 onward, it shifted focus to providing "resources for faculty, instructional, and organizational development."

\section{Methods}

To facilitate our analysis, an Access database was created, and all 587 chapters published in volumes 1 through 30 were entered into a table (fields included volume, year of publication, authors, author affiliation, author gender, chapter title, and TIA section title). Baseline data were generated from this initial table (including totals, averages, and frequencies).

For the topic analysis conducted on all chapter published in TIA (1982-2011b), all 587 chapter titles were entered into an Excel spreadsheet. In order to analyze the chapter topics, a coding scheme was developed based on the topic designations that were offered for the POD 
2012 conference: adjunct professional development; administration; assessment; diversity; faculty professional development; graduate student professional development; organizational development; POD professional development; programs; research; retention; the scholarship of teaching and learning; start-up; sustainability; teaching and learning; and technology (see table 10.2 for descriptions of each topic). We added two

\section{Table 10.2 Topic Coding Categories for Chapters, 1982-2011b}

Topic

Adjunct professional
development

Administration

Assessment

Diversity

Ethics $^{2}$

Faculty professional development

Graduate student professional development

Higher education ${ }^{a}$

Organizational development

POD professional development

\section{Description}

Practices, processes, theories, techniques, programs pertaining specifically to adjunct or part-time faculty development

Budgeting, funding, management, planning, performance appraisal, staff and faculty recruitment and retention, and other issues concerning the administration of a center or other unit

Measuring the effectiveness of an aspect of practice or outcomes in order to improve (designate other topics to indicate the subject of assessment-e.g., teaching and learning, programs, faculty professional development)

Addressing underrepresented or minority populations on campus, in the classroom, in administration

Discussions of the ethics of faculty development and teaching and learning practices, processes, theories, and techniques

Practices, processes, theories, techniques, programs pertaining to faculty development

Practices, processes, theories, techniques, programs pertaining specifically to graduate and professional student development

Faculty development in the larger framework of higher education; teaching and learning issues in higher education

Practices, processes, theories, or techniques related to the systemic development of institutions and organizations

Practices, processes, theories, techniques, programs pertaining to the development of those in the professions represented by POD (e.g., center staff, technologists) 


\section{Table 10.2. Continued}

Topic

Programs

Research

Retention

Scholarship of teaching and learning

Start-up

Sustainability

Teaching and learning

Technology

\section{Description}

Organization, implementation, practices, theories, techniques related to programs and services (in centers and other units)

Systematic, generalizable investigations into clearly defined questions, employing accepted methods for data collection and analysis

Practices, processes, theories, techniques related to retaining students and improving graduation rates

Practice of, results of, and programs supporting the scholarship of teaching and learning

Practices, processes, organizational ideas related to establishment and growth of centers, programs, or other projects

Incorporating principles of environmental and programmatic sustainability into educational development work

Practices, processes, theories, techniques related to classroom and other teaching and learning

Explorations of current and new technologies that can support teaching, program, or organizational development

${ }^{2}$ Topic coding categories added to the POD categories.

categories based on a brief review of the chapter: ethics, which we describe as discussions of the ethics of faculty development and teaching and learning practices, processes, theories, and techniques; and higher education, which we describe as faculty development in a larger framework of higher education or teaching and learning issues in higher education. We coded each chapter independently, with up to three categories chosen to represent the topics covered. When titles were insufficient to locate topics-for example, titles such as "Silk Purses" (1985) and "Do You See What I See?" (1994)—we looked to chapter abstracts to assist in categorizing each piece.

Given time and resource constraints, citation analysis was conducted on only one decade of TIA publications (2003-2011b); all 4,485 citations from the 205 chapters published in volumes 21 through 30 were entered into a separate table in Access. In order to analyze the citations, a coding scheme was developed to categorize the different citation sources and formats; the main categories are books, journals, monograph series, web 
materials, and other (e.g., conference papers, reports, magazines, newsletters, conference proceedings). We recognize that these categories are subjective; however, we cross-checked the citation source with publisher and library databases in order to verify categorizing conventions and the actual terms used when referring to published materials (e.g., TIA is categorized as a book, not a journal; New Directions in Teaching and Learning is categorized as a monograph series).

\section{Results}

Editorship, 1982-2011

In thirty years of publication, TIA has had thirty-three editors and fortyeight combined editors and associate editors. The current editorial structure of one editor and one associate editor was established in 1995 with volume 14. Before this structure, TIA would have as many as two editors and six associate editors for one volume.

Overall the number of total editors and associate editors has decreased over the years. Between 1995 and 1997, the associate editor served a oneyear term as associate and subsequently one year as editor of TIA. Since 1998, individuals serve four-year terms: each associate editor serves a twoyear associate editor term prior to a two-year term as editor. Early volumes of TIA also included "invited reviewers" who were listed in the editorial matter along with editors and associated editors (invited reviewers were not included in the data analysis of editors and associate editors).

LOCATION AND PROFESSIONAL ROLE The forty-eight unique TIA editors and associate editors over the course of the past three decades have been affiliated with forty-seven institutions; forty-five of those institutions are located in twenty-three states in the United States (the largest regions represented were the Midwest, with fourteen institutions represented, and the South, with twelve institutions represented), and two institutions located in Canada. Since 2002, editors and associate editors of TIA have held administrative or faculty positions, and several have also served within the POD organization on the Core Committee or as POD president.

GENDER An analysis of the gender of editors and associate editors in TIA over the past three decades illustrates that the leadership of women has remained steady at over two-thirds representation since TIA's original publication in 1982 (table 10.3). Women have predominated as editors and associate editors of TIA over three decades. Of the thirty-three editors 
Table 10.3 Gender of Editors and Associate Editors by Decade

\begin{tabular}{|c|c|c|c|c|c|c|}
\hline & \multicolumn{2}{|c|}{$\begin{array}{c}\text { Volumes } 1-10 \\
(1982-1991)(n=28)\end{array}$} & \multicolumn{2}{|c|}{$\begin{array}{c}\text { Volumes } 11-20 \\
(1992-2002)(n=22)\end{array}$} & \multicolumn{2}{|c|}{$\begin{array}{c}\text { Volumes 21-30 } \\
(2003-2011 \mathrm{~b})(n=6)\end{array}$} \\
\hline & Number & Percent & Number & Percent & Number & Percent \\
\hline Women & 17 & $61 \%$ & 16 & & 4 & $67 \%$ \\
\hline Men & 11 & $39 \%$ & 6 & $27 \%$ & 2 & $33 \%$ \\
\hline
\end{tabular}

of TIA over three decades, 70 percent were women and 30 percent were men. Similarly, of the sixteen associate editors of TIA over three decades, 62.5 percent were women and 37.5 percent were men.

\section{Contributors, $1982-2011$}

Of the 587 chapters published between 1982 and 2011 b, there were 808 unique authors, 57.2 percent of whom were unique first-listed authors. The number of authors published in TIA has increased over time, from 175 in the first decade (1982-1991), to 277 in the second (1992-2002), and 356 in the most recent decade (2003-2011b).

GENDER We analyzed the gender of authors in TIA both overall and by looking at only first authors and found a steady growth in the inclusion of women. Since its original publication, TIA has gone from an overall women authorship of 43.8 percent from 1982 to 1991 to 63.3 percent in the most recent decade (2003-2011b). The numbers of female first authors mirror this growth with 45.4 percent (1982-1991) and 68.3 percent (2003-2011b).

COLLABORATIVE AUTHORSHIP While a slight majority of chapters in TIA have had one author ( 51.4 percent), dual authorship is also prominent, with 29.8 percent of chapters authored by two individuals (see table 10.4). Collaborative authorship has also increased over time. Of the 185 chapters published between 1982 and 1991, 36.2 percent were authored by two or more individuals. In the volumes spanning 1992 to $2002,48.7$ percent of the 197 published chapters were authored by two or more individuals. In the most recent decade, 59.5 percent of the 205 chapters published were authored by two or more individuals. Single authorship has also decreased from approximately 64 percent in the decade 1982 to 1991 to approximately 40 percent in the most recent decade. Authorship of five to eight authors emerged in the 1990s and continues through the present day. 


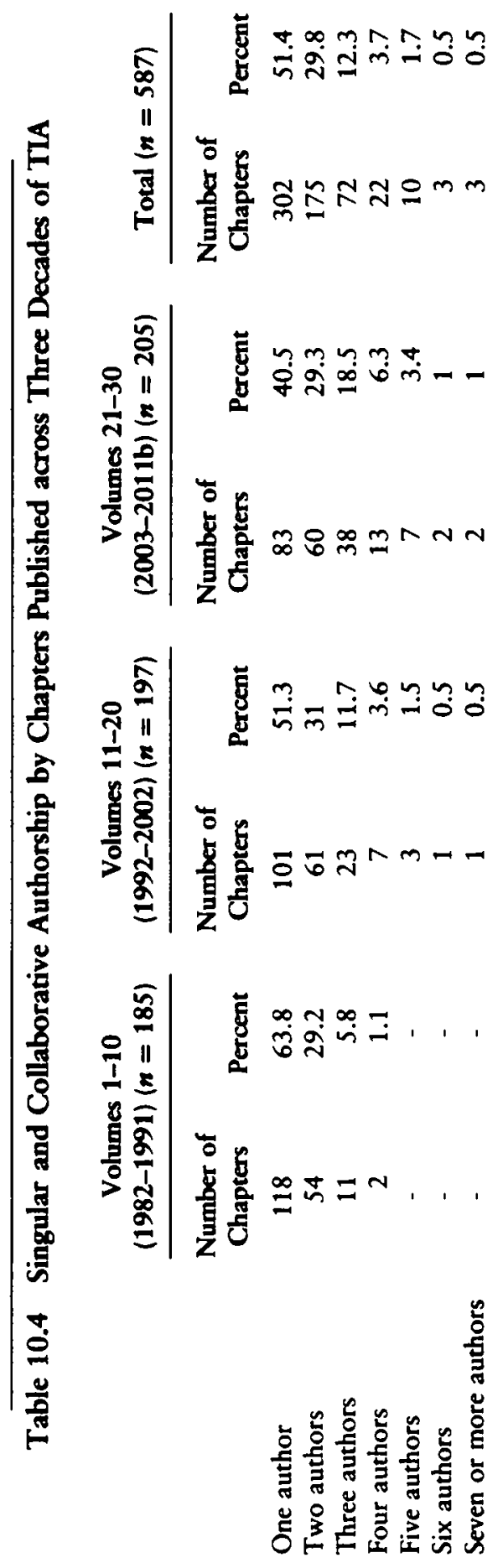


FREQUENCY OF PUBLICATION BY AUTHORS In the early years of TIA in particular, it was common for authors to publish multiple pieces in the journal over a period of years. For example, in the first decade of TIA's publication, about 31 percent ( 54 of 175 ) of the authors published in TIA had two or more chapters published in that decade. Between 1992 and 2002, 14.8 percent (41 of 277 ) authored multiple chapters, and between 2003 and $2011 \mathrm{~b}, 12.4$ percent ( 44 of 356 ) did so.

With the number of unique authors included in TIA at 175 in the first decade, to 277 in the second, and 356 in the most recent decade, the likelihood of authors publishing multiple chapters in TIA decreased by about 10 percent (see table 10.5). As the field of faculty development grew to include more practitioners, the proliferation of journals on teaching and learning in those decades may have offered more publication outlets on issues relevant to faculty development.

CROSS-INSTITUTIONAL AFFILIATIONS Similar to the increase in collaborative authorship in $T I A$, the number of cross-institutional affiliations for coauthored chapters has also grown over time, doubling between the first and last decades of publication. Although chapters written by authors from one institution still remain the most prevalent, at 66.7 percent of all TIA chapters published in the thirty years reviewed, it has become more common to see collaboratively written chapters with between two and five institutional affiliations (see table 10.6). Of the chapters published between 1982 and $1991,27.9$ percent were the result of cross-institutional collaborations. This number rose to 35.4 percent in the volumes published between 1992 and 2002. Contributions that brought together three or more institutional affiliations rose from 4.9 percent between 1982 and 1991 to 11.5 percent between 2003 and 2011 b.

INTERNATIONAL AFFILIATIONS Over the three decades, thirty-five chapters published in $T I A$ were written by one or more authors with international affiliations. These authors were affiliated with the following countries: Australia (three authors); Canada (twenty-five authors); Great Britain, including England and Scotland (four authors); Germany (three authors); Israel (three authors); and Thailand (three authors). From 1983 through 1991, ten internationally affiliated authors published in $T I A$, fifteen such authors did so between 1992 and 2002, and an additional ten internationally affiliated authors did so between 2003 and 2011 b.

SELF-CITATION OF AUTHORS IN TLA Of the 587 chapters published in TIA, 255 (43.4 percent) included author self-citations (see table 10.7). 


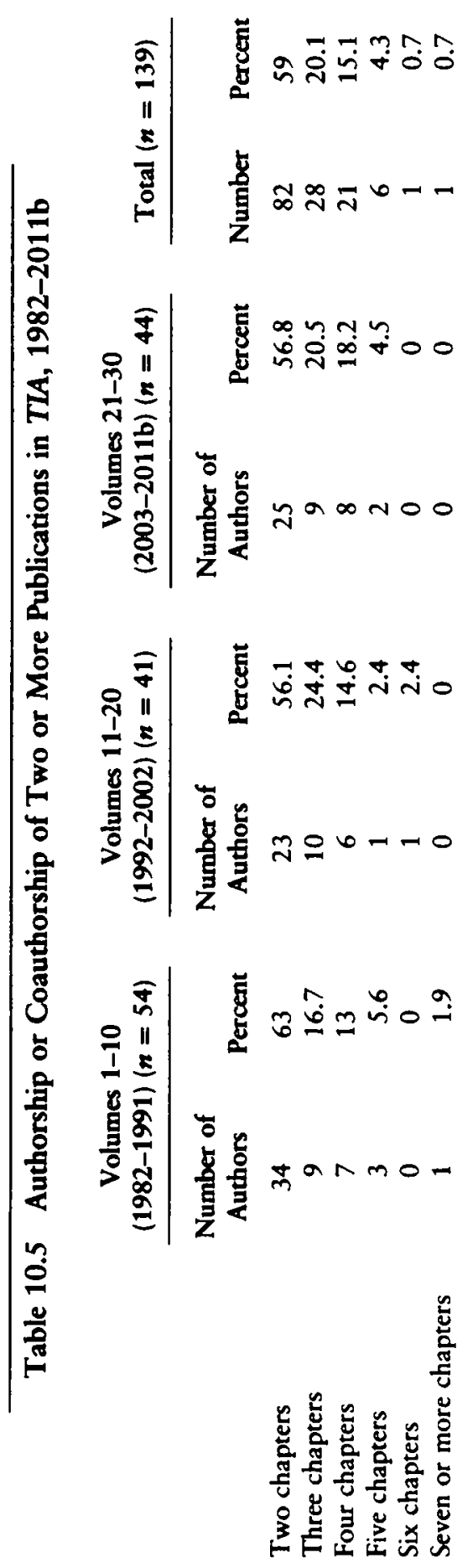




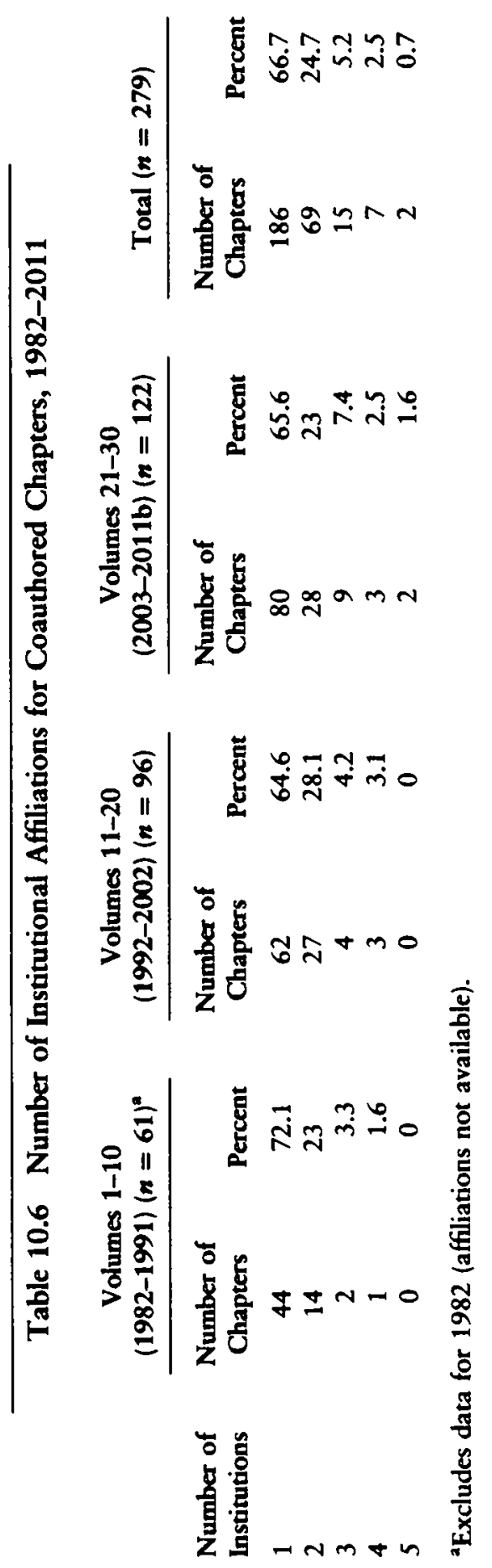


Table 10.7 TIA Chapters with Self-Citations, 1982-2011

\begin{tabular}{|c|c|c|c|c|c|c|c|c|}
\hline \multirow{3}{*}{$\begin{array}{l}\text { Chapters } \\
\text { with self- } \\
\text { citations }\end{array}$} & \multicolumn{2}{|c|}{$\begin{array}{c}\text { Volumes } 1-10 \\
(1982-1991) \\
(n=185) \\
\end{array}$} & \multicolumn{2}{|c|}{$\begin{array}{c}\text { Volumes } 11-20 \\
(1992-002) \\
(n=197) \\
\end{array}$} & \multicolumn{2}{|c|}{$\begin{array}{c}\text { Volumes 21-30 } \\
(2002-2011 \mathrm{~b}) \\
(n=205) \\
\end{array}$} & \multicolumn{2}{|c|}{ Total $(n=587)$} \\
\hline & Number & Percent & Number & Percent & Number & Percent & Number & Percent \\
\hline & 58 & 31.4 & 96 & 48.7 & 101 & 49.3 & 255 & 43.4 \\
\hline
\end{tabular}

Self-citations have increased over the decades, with an average of 3.2 selfcitations per chapter, ranging from 1 to 21 citations in a given chapter, and a minimum of one self-citation. Authors who have published on specific topics in both TIA and other publications are the ones who selfcite, thus indicating expertise in an area.

\section{Chapter Topic Analysis: How TIA Topics Have Changed over Time}

After independently coding 587 chapters using eighteen coding categories (specified in the methods section; see table 10.2), coding each chapter with up to three of the eight coding categories, we had an 89 percent agreement rate on one or more of the three categories. All chapters were coded into at least one category (see table 10.8 for a data summary). According to this categorizing method, the majority of the chapters published in TIA over the three decades have consistently focused on faculty professional development ( 274 chapters), teaching and learning ( 252 chapters), POD professional development (179 chapters), and programs (157 chapters). These results are not surprising given the aims of TIA and the intended audience of POD members. Perhaps more interesting are the chapter themes that were infrequent: sustainability (10 chapters), ethics ( 8 chapters), faculty development program start-up ( 8 chapters), adjunct professional development ( 6 chapters), and student retention ( 1 chapter). There has been an increase over the past three decades in the number of chapters published that focus on POD professional development, assessment, program start-up, and adjunct professional development (see table 10.8).

Noteworthy are the topics that we thought would be more prominent across the decades, including assessment, scholarship of teaching and learning, and technology, which seem to have risen in popularity and 
predominate in contemporary discussion in other publications. For instance, technology was the focus of less than 5 percent of the chapters published in TIA. These are gaps in the literature that perhaps future TIA authors will consider. Overall, these findings raise the questions of how TIA has responded to trends in higher education and will do so in the future.

CITATION ANALYSIS Of the 587 chapters analyzed, 56 (nine percent) include no cited references to other literature in the field. The majority without cited references were published before 2000 , with only two chapters (one in 2002 and one in 2010) citing no outside literature. The average number of citations in volumes 1 through 30 (1982-2011b) is 15.8 citations per TIA chapter (see figure 10.2). The number of citations has increased over the past three decades of TLA, from an average of 9.85 citations in the 1980 s to an average of 21.81 citations in the 2000 s.

Based on an analysis of 4,485 citations from 205 chapters in ten volumes (21-30), fifty-three authors and two organizations have been cited ten or more times between 2003 and 2011b. Of these, six authors have been cited thirty or more times in TIA chapters (Hutchings, Schulman, Boyer, Cox, Sorcinelli, and Boice). Seven authors have been cited twenty to twenty-nine times in TIA chapters (Millis, Palmer, Weimer, Rice, Nuhfer, Fink, and Huber). Forty authors and two organizations (Association of American Colleges Universities and POD) have been cited ten to nineteen times in TIA chapters.

The majority of sources cited by authors in volumes 21 through 30 (2003-2011b) were books (47 percent of all citations) and journals (29 percent). The most cited source was TIA, cited 258 times; followed by the monograph series New Directions for Teaching and Learming, cited 142 times; and the magazine Change, cited 89 times. The five most cited journals were the Journal of Higher Education (cited 65 times), Innovations in Higher Education (cited 39 times), Research in Higher Education (cited 31 times), College Teaching (cited 28 times), and the International Journal for Academic Development (cited 23 times). (See figure 10.3.)

VISIBILITY OF TIA Further exploration reveals that $T I A$ is infrequently cited in the teaching and learning journals that are most frequently cited in TIA. Through an analysis of the top five journals over a five-year period (2007-2011), we found that only three TIA chapters were cited in the Journal of Higher Education; twelve TIA chapters in Innovations in Higher Education; one TIA chapter in Research in Higher Education; six TIA chapters in College Teaching; and seven TIA chapters in the 


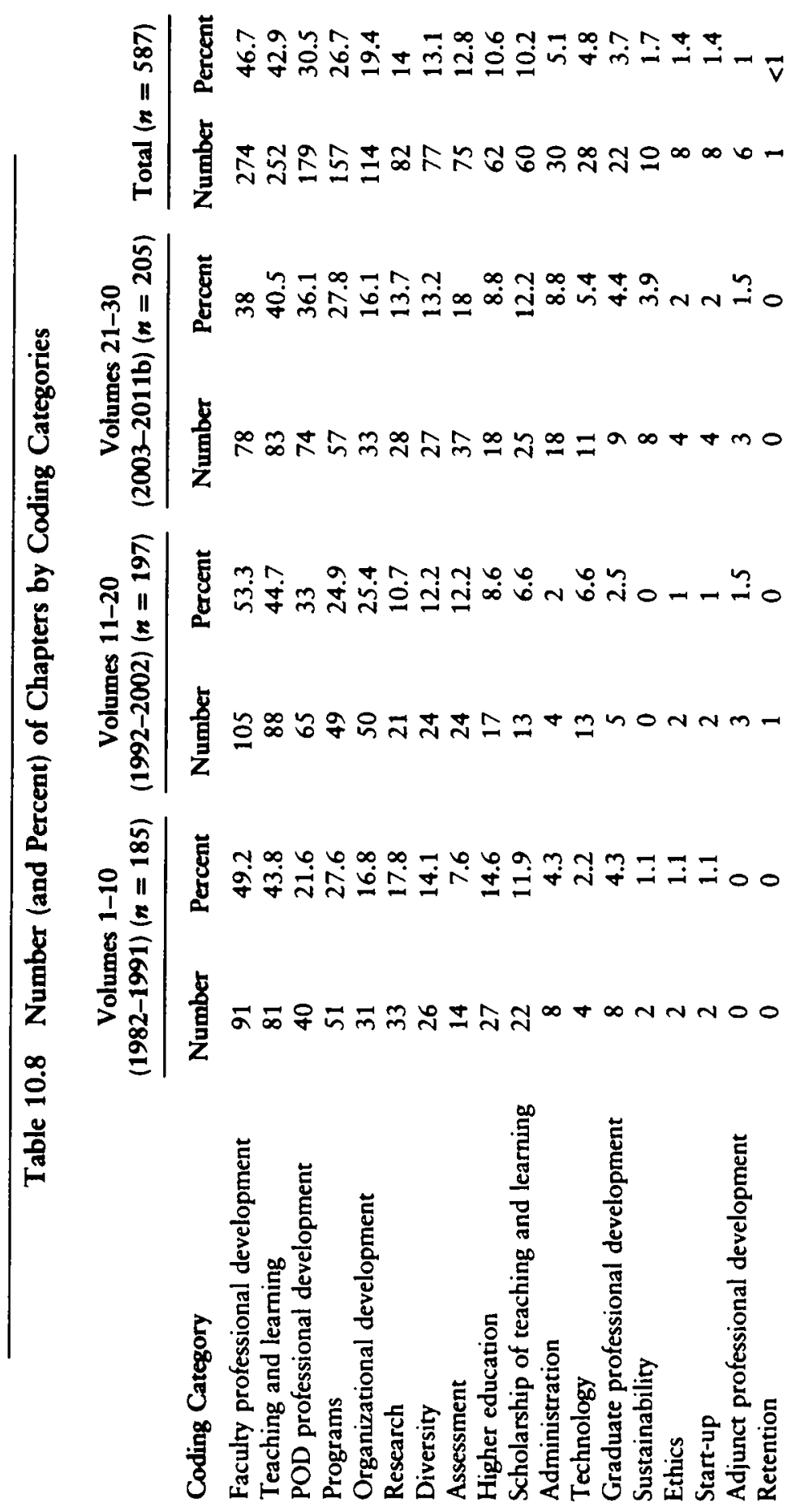


Figure 10.2 Average Number of Citations per TLA Volume, 1982-2011b

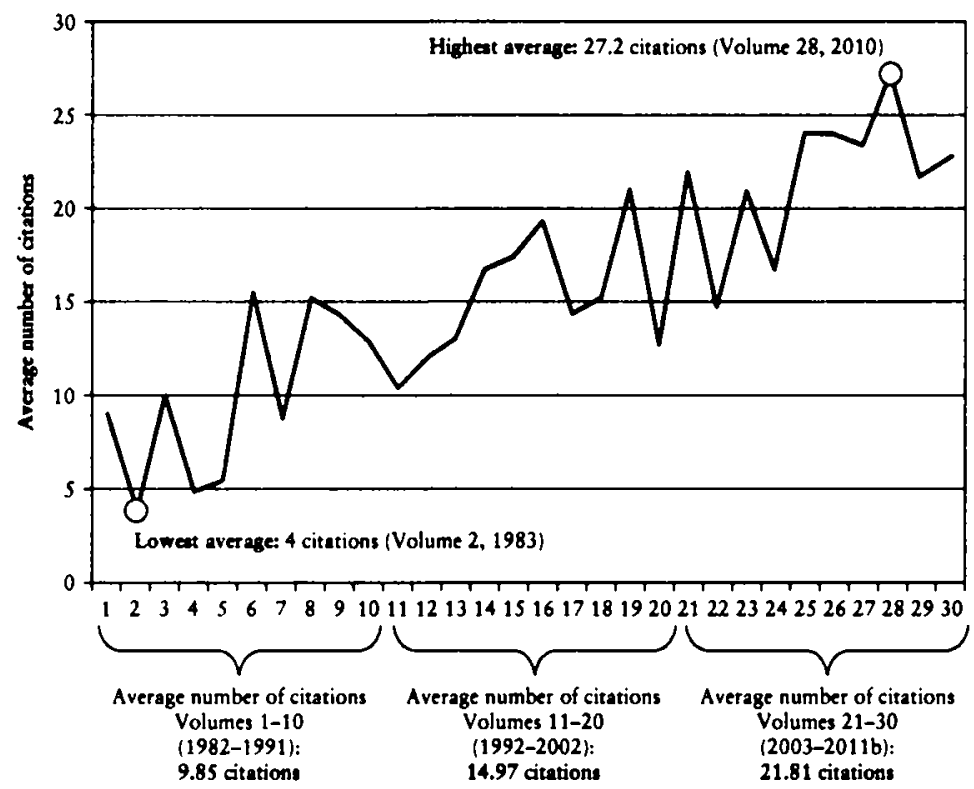

Figure 10.3 Types of Sources Cited in TIA, 2003-2011b

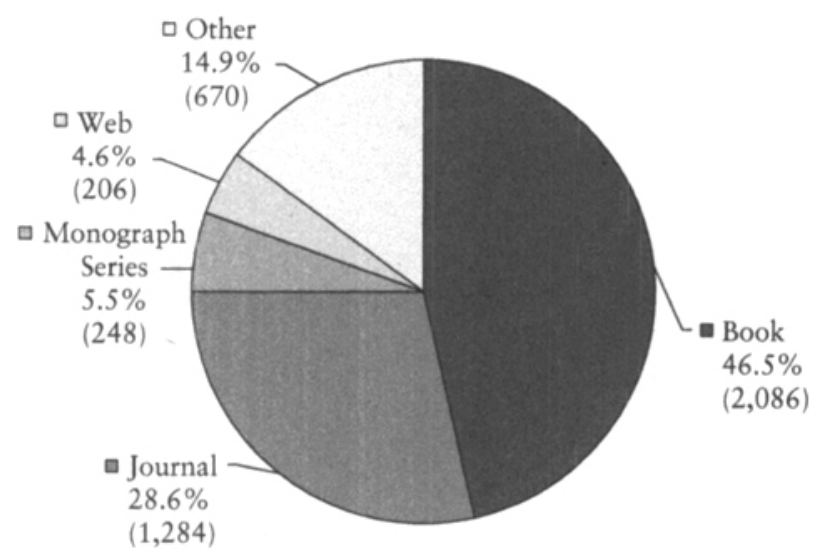

Note: $N=4,485$. The category "Other" includes conference papers (3.1 percent); reports ( 3 percent); magazines ( 2.7 percent); newsletters ( 1.7 percent); newspapers (1.4 percent); and occasional papers, dissertations, unpublished manuscripts, center for teaching and learning materials, media, conference proceedings, POD Ethical Guidelines, keynote presentations, email communication, survey, directory, and software manuals (all under 0.5 percent). 
International Journal for Academic Development. Comparatively, the top five journal citations were 4 percent of overall citations in TIA chapters, whereas $T I A$ citations comprised less than 1 percent of the citations in the top five journals. In a five-year period, TIA was cited 29 times in 19 chapters out of a total of 25,727 citations and 881 chapters analyzed. Not surprisingly, the authors citing TIA in other journals were frequently those who had been previously published in TIA (though they rarely cited their own work).

\section{Limitations}

The data analysis in this study has some limitations. First, all efforts were made to ensure that the TIA data were properly entered into a database; however, data entry errors and resulting calculation errors may be a slight possibility. Second, although we used the POD conference themes to categorize TIA chapters, the qualitative analysis can be considered subjective. For instance, we interpreted the categories differently, and this led to differences in how chapters were coded; moreover, no interrater reliability was established for conference themes. Third, the citation analysis is limited to one decade of TIA (2003-2011b), as is the exploration of other sources that cite TIA chapters. This is due to time and resource constraints, though future researchers may want to tackle the citations of all chapters published in TIA between 1982 and 2002.

\section{Conclusion}

This study examined trends over three decades of TIA publication: 1982 to $2011 \mathrm{~b}$. By reflecting backward, we have a better understanding of the history of TIA as a publication for professional developers to publish in and as a resource to inform their practice. Noteworthy trends have included the regularization of editorship roles, a shift in target audience, an increase in collaborative authorship, an increase in the number of citations referenced per chapter, consistent emphasis on particular chapter topics and themes, and an increase in self-citation practices.

\section{Opportunities for POD Members}

Brew (2002) notes the "centrality of inquiry to everything developers do" (p. 116). For many faculty developers, TIA has played a significant role in promoting the inquiries of POD members and contributing to POD professional development. Research continues to be central to the practice 
of academic developers and a matter of credibility in the field. Reflecting forward, it is worth exploring the potential ways in which TIA, through its editors, authors, and readers, contributes to moving research on teaching and learning forward in higher education. There appear to be great opportunities for collaboration, increased visibility of TIA beyond POD members, and potential authors to write about underresearched topics and themes.

There are also several opportunities for further studies regarding TIA. First, a more in-depth citation analysis covering all decades of TIA's publication may lead to additional findings regarding how TIA has followed various citation trends, such as the rise in online references. Second, additional coding is needed on the chapters that are being referenced by other higher education journals. Because these chapters are so few, looking back beyond five years to find which chapter themes have been the most prevalent in these citations could yield new information about how authors are using TIA citations in their work and how TIA is being represented in other scholarly publications. Based on these analyses, we offer the following additional recommendations.

\section{Recommendations}

While researching three decades of TIA, we encountered difficulty accessing past issues; however, the discovery of digitized volumes (19821998) hosted on the University of Nebraska-Lincoln DigitalCommons open access site (http://digitalcommons.unl.edu/podimproveacad/) proved to be indispensable. Making TIA more accessible, ideally online, is worth exploring if the intent is for the knowledge generated to be shared with a wider audience. It is imperative that TIA chapters be more easily found and referenced.

TIA is said to be the most important peer-reviewed resource for professional developers. Yet the questions posed by this research study persist: Who is citing TIA? What are the latest developments? The majority of TIA citations found in other higher education publications are in chapters by POD members. Faculty development researchers should cite TIA whenever applicable and whenever possible in their own work, but also in work that they coauthor with others outside of the field who may not be familiar with TIA. Consideration should be given to citation indexing, as there is currently no way to determine the impact that TIA is having on the literature and the field. By making TIA both accessible and increasing its visibility, there may be increased potential for cross-fertilization, collaboration, creation of new knowledge, and advancement of the field. 
We embarked on this research study eager to discover the history of TIA. Our exploration of the editor, author, chapter, and citation trends proved to be a time-consuming exercise but one that TIA may consider routinely engaging in, as such introspection is what may sustain the publication by attracting a new generation of readers and authors.

\section{REFERENCES}

Boice, R. (2000). Advice for new faculty members: Nibil nimus. Boston: Allyn and Bacon.

Blancher, A. T., Buboltz, W. C., \& Soper, B. (2010). Content analysis of the Journal of Counseling and Development, volumes 74-84. Journal of Counseling and Development 88, 139-145.

Brew, A. (2002). Research and the academic developer: A new agenda. International Journal for Academic Development, 7, 112-122.

Pelsma, D., \& Cesari, J. P. (1989). Content analysis of the Journal of Counseling and Development, volumes 48-66. Journal of Counseling and Development, 67, 275-278.

Tight, M. (2009). The structure of academic research: What can citations studies tell us? In A. Brew \& L. Lucas (Eds.), Academic research and researchers (pp. 55-65). New York, NY: McGraw-Hill.

Williams, M. E., \& Buboltz, W. C. (1999). Content analysis of the Journal of Counseling and Development, volumes 67-74. Joumal of Counseling and Development 77, 344-349. 